\title{
Fully automated method for the liquid chromatographic-tandem mass spectrometric determination of cyproterone acetate in human plasma using restricted access material for on-line sample clean-up
}

\author{
B. Christiaens ${ }^{\mathrm{a}}$, M. Fillet ${ }^{\mathrm{a}}$, P. Chiap ${ }^{\mathrm{a}}$, O. Rbeida ${ }^{\mathrm{a}}$, A. Ceccato ${ }^{\mathrm{b}}$, B. Streel ${ }^{\mathrm{b}}$, \\ J. De Graeve ${ }^{\mathrm{c}}$, J. Crommen ${ }^{\mathrm{a}, *}, \mathrm{Ph}$. Hubert ${ }^{\mathrm{a}}$ \\ a Department of Analytical Pharmaceutical Chemistry, Institute of Pharmacy, University of Liège, CHU, \\ B-36 Avenue de l'Hôpital 1, B-4000 Liège, Belgium \\ ${ }^{\mathrm{b}}$ Galephar MF, Rue du Parc Industriel, B-6900 Marche-en-Famenne, Belgium \\ ${ }^{\mathrm{c}}$ Department of Environmental and Industrial Toxicology, University of Liège, B 35, Avenue de l'Hôpital 13, B-4000 Liège, Belgium
}

Available online 30 July 2004

\begin{abstract}
A new automated method for the quantitative analysis of cyproterone acetate (CPA) in human plasma has been developed using on-line solid phase extraction (SPE) prior to the LC-MS/MS determination. The method was based on the use of a pre-column packed with internal-surface reversed-phase material (LiChrospher RP-4 ADS, $25 \mathrm{~mm} \times 2 \mathrm{~mm}$ ) for sample clean-up coupled to LC separation on an octadecyl silica stationary phase by means of a column switching system. A $30 \mu l$ plasma sample volume was injected directly onto the pre-column using a mixture of water, acetonitrile and formic acid (90:10:0.1 (v/v/v)) adjusted to $\mathrm{pH} 4.0$ with diluted ammonia as washing liquid. The analyte was then eluted in the back-flush mode with the LC mobile phase consisting of water, methanol and formic acid (10:90:0.1 (v/v/v)). The dispensing flow rates of the washing liquid and the LC mobile phase were $300 \mu 1 \mathrm{~min}^{-1}$. Medroxyprogesterone acetate (MPA) was used as internal standard. The MS ionization of the analytes was achieved using electrospray (ESI) in the positive ion mode. The pseudomolecular ionic species of CPA and MPA (417.4 and 387.5) were selected to generate daughter ions at 357.4 and 327.5, respectively. Finally, the developed method was validated according to a new approach using accuracy profiles as a decision tool. Very good results with respect to accuracy, detectability, repeatability, intermediate precision and selectivity were obtained. The LOQ of cyproterone acetate was $300 \mathrm{pg} \mathrm{ml}^{-1}$. (C) 2004 Elsevier B.V. All rights reserved.
\end{abstract}

Keywords: Validation; Mass spectrometry; Cyproterone acetate

\section{Introduction}

The on-line coupling of mass spectrometry to liquid chromatography (LC-MS) is a powerful technique used for drug determination in various biological fluids [1-3]. Its high sensitivity and selectivity are well-known advantages. Some of them also involve the on-line coupling of solid phase extraction to liquid chromatography for sample clean-up [4-5].

The column-switching technique is an interesting alternative to off-line approaches for the preparation of biological samples. The role of precolumn is to retain selectively the

\footnotetext{
* Corresponding author. Tel.: +32 4 3664346; fax: +32 43664347 .

E-mail address: jcrommen@ulg.ac.be (J. Crommen).
}

analytes. After rotation of the switching valve, the analytes are transferred to the analytical column to be individually quantified [6].

A new concept in LC packing materials for bioanalytical purposes was introduced in 1985 by Pinkerton and coworkers [7,8]. Boos et al. introduced a new class of restricted access material [9-12] called alkyl-diol silica (ADS) that can be packed in small precolumns used for the clean-up of protein-rich samples in column switching systems.

Such restricted access supports, packed in small precolumns, have been successively applied to the individual determination of drugs enantiomers in plasma samples $[13,14]$.

The drug molecule studied in this paper is cyproterone acetate (6-chloro- $1 \beta, 2 \beta$-dihydro- $17 \alpha$-hydroxy- $3^{\prime} \mathrm{H}$ - 
cyclopropa[1,2]-pregna-1,4,6-triene-3,20-dione acetate) [24]. In practice, the usual dosage is $100 \mathrm{mg}$, twice daily for the treatment of prostate carcinoma [15], or $2 \mathrm{mg}$ for the treatment of woman acne and hirsutism [16]. The average concentration of CPA detected in plasma after the administration of a dosage of $2 \mathrm{mg}$ of CPA per day (Diane- $35^{\circledR}$ ) in combination with $35 \mu \mathrm{g}$ of an estrogenic compound leads to a maximum plasma level $\left(C_{\max }\right)$ of $15 \mathrm{ng} \mathrm{ml}^{-1}$ at $1.6 \mathrm{~h} \mathrm{[17].}$

Several LC methods have been developed for the quantitative analysis of CPA in pharmaceutical forms $[18,19]$ or in biological fluids using liquid-liquid extraction [20-22] or solid-phase extraction in a column switching system [23,24] for sample clean-up. For all these bioanalytical methods based on UV detection, the limit of quantification was higher than $1 \mathrm{ng} \mathrm{ml}^{-1}$. The introduction of MS detection should lead to a significant improvement in detectability and selectivity as well as to a reduction of the analysis time.

A novel approach based on the accuracy profile as decision tool has been used for the validation of the present method $[25,26]$. By this approach, using two-sided 95\% $\beta$-expectation tolerance intervals for the total measurement error, the performance of the procedure can be better visualized.

The aim of this work is to develop and validate a fully automated coupled-column LC method for the determination of cyproterone acetate in human plasma using MS/MS detection in order to improve the sensibility obtained in our previous work [24].

\section{Experimental}

\subsection{Chemical, reagents and apparatus}

Cyproterone acetate (CPA) and medroxyprogesterone acetate (MPA) were purchased from Sicor (Lerma, Mexico) and Certa (Braine-L'Alleud, Belgium), respectively. Acetonitrile, methanol, ammonium acetate, diluted ammonia and formic acid were purchased from Merck KGaA (Darmstadt, Germany). The water was purified on a Milli-Q system (Millipore, Bedford, MA, USA) (Fig. 1).

The analytical column $(100 \mathrm{~mm} \times 2 \mathrm{~mm}$ i.d. $)$ was packed with OmniSpher C18 (3 $\mu \mathrm{m})$ stationary phase in a ChromSep system from Varian (Sint-Katelijne-Waver, Belgium). The mobile phase was a mixture of water, methanol and formic acid (10:90:0.1 (v/v/v)) delivered at $0.3 \mathrm{ml} \mathrm{min}^{-1}$.

The LiChroCart precolumn $(25 \mathrm{~mm} \times 2 \mathrm{~mm}$ i.d. $)$ packed with LiChrospher RP-4 ADS $(25 \mu \mathrm{m})$, was purchased from Merck KGaA (Darmstadt, Germany). The washing liquid was a mixture of water, acetonitrile and formic acid (90:10:0.1 $(\mathrm{v} / \mathrm{v} / \mathrm{v})$ ) adjusted to $\mathrm{pH} 4.0$ and dispensed at $0.3 \mathrm{ml} \mathrm{min}^{-1}$.

Both precolumn and analytical column were thermostated at $25^{\circ} \mathrm{C}$ in the temperature controlled oven. The sample rack was cooled at $15^{\circ} \mathrm{C}$.

The prevalidation and validation data were analysed with e.noval, software version 1.0. (Arlenda, Belgium).
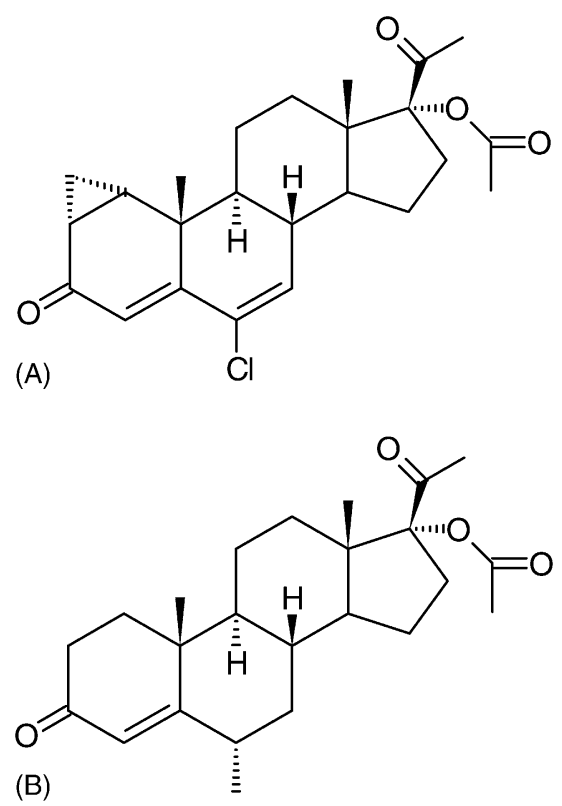

Fig. 1. (A) Structure of cyproterone acetate. Molecular weight: 416.95; molecular formula: 6-chloro-17-hydroxy-1 $\alpha, 2 \alpha$-methylenepregna4,6-diene-3,20-dione acetate; (B) structure of medroxyprogesterone acetate; molecular weight: 386.53 ; molecular formula: $(6 \alpha)$-17-hydroxy-6methylpregn-4-ene-3,20-dione acetate.

An integrated column switching system coupled to a capillary liquid chromatographic apparatus (HP Series 1100, Agilent Technologies) consisting in a degasser, a micro quaternary pump, a micro ALS model as injector and finally an additional integrated six-port micro switching valve (Colcom model) was used. The washing liquid used for the sample pre-treatment was delivered by a model pump 302 from Gilson (Rijswijk, The Netherlands).

The MS/MS ionization of the analytes was achieved by electrospray (ESI) in the MRM positive ion mode using a triple quadrupole mass detector (Quatro Ultima) purchased from Micromass (Wijtenshaw, UK). The main MS parameters were as follows: source temperature: $150^{\circ} \mathrm{C}$, capillary and cone voltages: 3.20 and $50 \mathrm{~V}$, respectively, desolvation temperature: $400^{\circ} \mathrm{C}$, cone gas flow: $170 \mathrm{~L} \mathrm{~h}^{-1}$, and finally the desolvation gas flow: $410 \mathrm{~L} \mathrm{~h}^{-1}$. The resolution of the different quadrupoles was also optimized $(<0.5 \mathrm{amu})$. The pseudomolecular ionic species of CPA and MPA (417.4 and 387.5 ) were selected to generate daughter ions at 357.4 and 327.5 , respectively.

The plasma sample was first centrifuged at $4500 \mathrm{rpm}$ for $10 \mathrm{~min}$ and $900 \mu \mathrm{l}$ of the supernatant were used for sample spiking. All the other operations were then executed automatically.

The sample preparation was performed in two steps:

(1) Injection and washing of sample: Thirty microliters of aliquot of plasma were injected. The sample was washed for $14 \mathrm{~min}$ with a mixture of water, acetonitrile and formic acid (90:10:0.1 (v/v/v)) adjusted to $\mathrm{pH} 4.0$ with 
diluted ammonia. The flow rate was $0.3 \mathrm{ml} \mathrm{min}^{-1}$. Macromolecules and hydrophilic endogenous compounds were not retained and eliminated to the waste. The analytes were retained on the precolumn. Meanwhile, the analytical column was equilibrated with the analytical LC mobile phase.

(2) Elution of the analytes from the precolumn and LC analysis: After these $14 \mathrm{~min}$, the valve was switched in order to connect the precolumn to the analytical column. The analytes were eluted in the back-flush mode by the LC mobile phase. Four minutes later, the switching valve was returned to its initial position and the precolumn was reequilibrated with the washing liquid. In the mean time, the LC-MS/MS analysis was performed on the analytical column.

\subsection{Solutions}

\subsubsection{Stock solution of internal standard and cyproterone acetate}

A stock solution containing $1 \mathrm{mg} \mathrm{ml}^{-1}$ of medroxyprogesterone acetate was prepared in acetonitrile. This solution was diluted in a mixture of $90 \%$ of water and $10 \%$ of acetonitrile in order to obtain an intermediate solution of $50 \mathrm{ng} \mathrm{ml}^{-1}$. The same procedure was performed with cyproterone acetate.

\subsubsection{Solutions used for method pre-validation and validation}

One $\mathrm{ml}$ of the stock solution of cyproterone acetate was then diluted with a mixture of water and acetonitrile (90:10 $(\mathrm{v} / \mathrm{v}))$ in a $100 \mathrm{ml}$ flask in order to obtain a daughter solution $\left(10 \mu \mathrm{g} \mathrm{ml}^{-1}\right)$. This solution was then diluted with acetonitrile in order to obtain intermediate concentrations used for plasma spiking.

For both pre-validation and validation, $50 \mu \mathrm{l}$ of each solution were spiked to $900 \mu \mathrm{l}$ of human plasma samples over the considered range (from 0.3 to $50 \mathrm{ng} \mathrm{ml}^{-1}$ ). Fifty microliters of the internal standard were then added to the samples, in order to have a final concentration of $2.5 \mathrm{ng} \mathrm{ml}^{-1}$.

For pre-validation, seven concentration levels were selected, one at the estimated limit of quantification $\left(0.5 \mathrm{ng} \mathrm{ml}^{-1}\right)$, one below the selected LOQ $\left(0.3 \mathrm{ng} \mathrm{ml}^{-1}\right)$, one at the maximal concentration studied $\left(50 \mathrm{ng} \mathrm{ml}^{-1}\right)$ and four intermediate concentrations $\left(1,5,10\right.$ and $\left.25 \mathrm{ng} \mathrm{ml}^{-1}\right)$. In the calibration range three repetitions were made at each concentration level and three series of calibration were performed in the pre-validation.

For validation, five concentration levels were selected for the calibration curves, one at the estimated limit of quantification $\left(0.3 \mathrm{ng} \mathrm{ml}^{-1}\right)$, one at the maximal concentration studied $\left(50 \mathrm{ng} \mathrm{ml}^{-1}\right)$ and four intermediate concentrations $(0.5,1,10$ and $25 \mathrm{ng} \mathrm{ml}^{-1}$ ). The sequence of injections consisted in two repetitions of each concentration level for 3 days.

Six concentration levels $(0.3,0.5,1,10,25$ and $50 \mathrm{ng} \mathrm{ml}^{-1}$ ) were selected for the validation standards in or- der to cover the whole range. Three repetitions were made at each concentration level for 3 days.

\section{Results and discussion}

Owing to the use of a narrow bore column and the on-line coupling to MS/MS, several parameters of the previously published method had to be adapted [24] that led to a reevaluation of both LC conditions and sample pre-treatment.

\subsection{Optimization of the LC conditions}

The optimization of the LC conditions was carried out by evaluating three different stationary phases: a Purospher ${ }^{\circledR}$ STAR RP-18 e $(125 \mathrm{~mm} \times 2.0 \mathrm{~mm}$ i.d., $5 \mu \mathrm{m})$ from Merck KGaA; a Nucleosil ${ }^{\circledR} 100-5$ C18 AB (125 mm $\times 2.0 \mathrm{~mm}$ i.d., $3 \mu \mathrm{m})$ from Macherey-Nagel and an OmniSpher ${ }^{\circledR} \mathrm{C} 18$ $(100 \mathrm{~mm} \times 2.0 \mathrm{~mm}$ i.d., $3 \mu \mathrm{m})$ from Varian. The latter gave the best results in terms of peak efficiency and symmetry and was selected.

Optimized results with respect to sensitivity (gain by a factor two) were obtained with methanol. The addition of formic acid $(0.1 \%)$ was required to improve the ionization efficiency.

A mobile phase consisting of a mixture of $75 \%$ of methanol and $25 \%$ of water allowed to separate cyproterone acetate and medroxyprogesterone acetate. The addition of $0.1 \%$ formic acid increased the detector response of the analytes comparing with mobile phases adjusted to $\mathrm{pH} 4.0$ and 7.0 .

However, after 200 automated injections, a relatively important carry-over effect $( \pm 1 \%)$ was observed at the retention times of CPA and MPA. The interference could be reduced by selecting a LC mobile phase made of water, methanol, and formic acid (10:90:0.1 (v/v/v)). A decrease of the flowrate and an increase of the column temperature did not give rise to any significant improvement. Therefore, these parameters were kept at their initial values. Under these conditions, the carry-over was reduced to less than $0.3 \%$ (for both substances), even after injections of standard solutions containing $50 \mathrm{ng} \mathrm{ml}^{-1}$ of CPA and $2.5 \mathrm{ng} \mathrm{ml}^{-1}$ of MPA. The high proportion of methanol of the mobile phase led to the coelution of the analyte and the internal standard from the analytical column. The principal risk of this co-elution is a potential loss of ionization efficiency at low concentrations of the analyte due to the presence of high concentrations of the internal standard. However, no significant loss of ionization efficiency was observed with CPA in the presence of MPA.

\subsection{Development of the sample preparation procedure}

In order to develop a method for the determination of CPA in human plasma using a column-switching system with a precolumn packed with restricted access material, it 
was necessary to determine the most appropriate switching times and to optimize the composition of the washing liquid [24].

\subsubsection{Elution profile of CPA and selection of the washing liquid}

The response intensity for CPA was higher with a washing liquid consisting of $90 \%$ of water, $10 \%$ of acetonitrile and $0.1 \%$ of formic acid than without formic acid. However, the results were improved with the use of a liquid adjusted to $\mathrm{pH}$ 4.0 instead of 7.0. Under these conditions, the retention time of CPA was higher than 120 min.

\subsubsection{Elution profile of blank plasma}

The determination of the elution profile of blank plasma was performed using a UV detector set at 220 and $280 \mathrm{~nm}$, respectively, and by injecting $30 \mu \mathrm{l}$ of blank plasma samples. The flow-rate was kept at $0.3 \mathrm{ml} \mathrm{min}^{-1}$.

A complete elution of proteins was achieved within $5 \mathrm{~min}$ with a washing liquid made of water, acetonitrile and formic acid (90:10:0.1 (v/v/v)) adjusted to $\mathrm{pH} 4.0$ with diluted ammonia. The valve switching time had to be increased to $14 \mathrm{~min}$ in order to reduce the carry over effect.

\subsubsection{Analyte transfer}

The two target substances were rapidly eluted from the RP-4 ADS precolumn due to the much stronger eluting strength of the LC mobile phase (water-methanol-formic acid, 10:90:0.1 (v/v/v)). It takes about 4 min to quantitatively transfer CPA and MPA from the precolumn to the analytical column.

\subsubsection{Absolute recovery}

The absolute analyte recovery was determined by comparing peak areas obtained from freshly prepared plasma samples and those found by direct injection of standard solutions. The absolute recovery for CPA was estimated at $99.4 \pm 1.4 \%$ $(n=9)$ in the whole concentration range.

\subsection{Method validation}

\subsubsection{Stability}

Samples exhibited good stability after a 1 month storage at $-18{ }^{\circ} \mathrm{C}$ and $48 \mathrm{~h}$ in the auto-sampler kept at $15^{\circ} \mathrm{C}$. The accuracy calculated at three concentration levels $(0.3,1.0$ and $50.0 \mathrm{ng} \mathrm{ml}^{-1}$ ) were estimated at $94.6 \pm 1.6 \%(n=9), 96.9 \pm$ $1.3 \%(n=9)$ and $100.4 \pm 1.1 \%(n=9)$, respectively.

\subsubsection{Selectivity}

The selectivity was evaluated by testing six different sources of human plasma. Fig. 2 illustrates the selectivity by comparing a blank plasma sample, one spiked with both CPA and MPA and finally a plasma sample from a dosed patient at $T_{24 \mathrm{~h}}$ spiked with the internal standard. Under the optimized experimental conditions, the mean retention factors for CPA and MPA were both equal to 3.0, as the two compounds coelute. A slight constant carry over effect was still observed, being $<0.3 \%$ for both substances after analysis of a plasma sample spiked with $50 \mathrm{ng} \mathrm{ml}^{-1}$ of CPA and $2.5 \mathrm{ng} \mathrm{ml}^{-1}$ of MPA.

\subsubsection{Response function [25-27]}

The validation results of the response function are presented in Table 1. A weighted linear regression $\left(1 / X^{2}\right)$ with
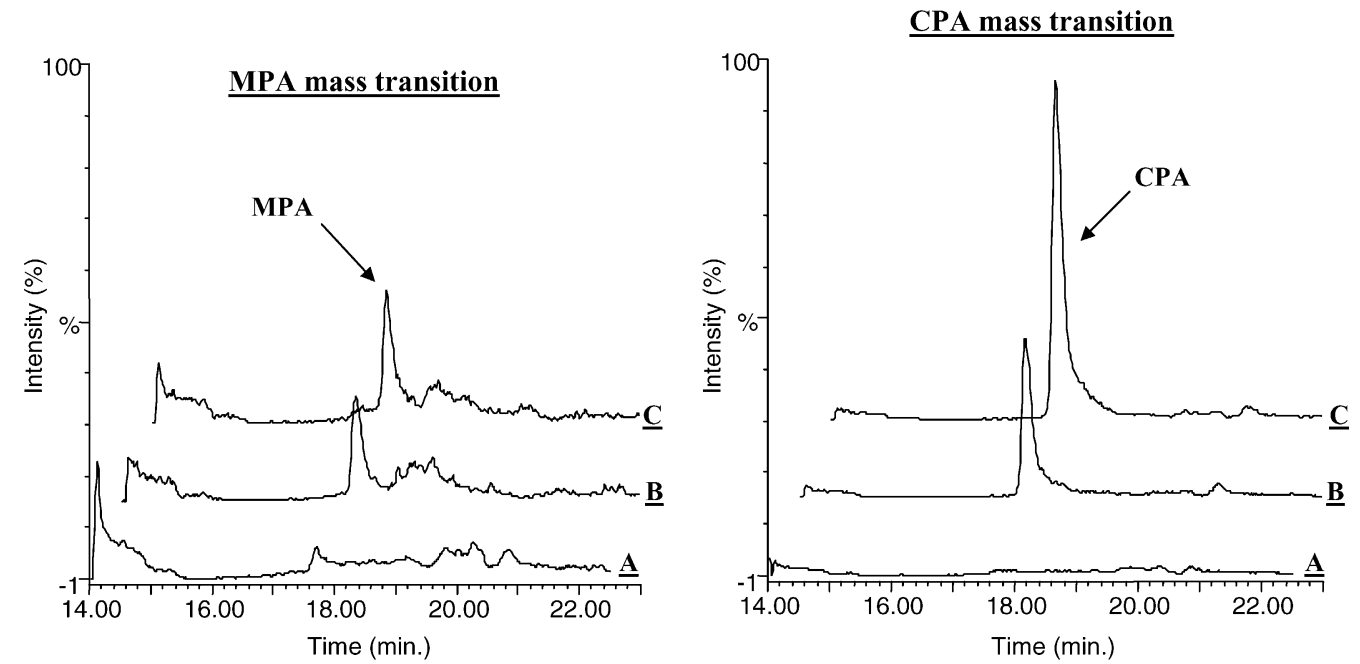

Fig. 2. Method selectivity for the determination of cyproterone acetate in human plasma. Samples: (A) blank plasma; (B) spiked plasma with 25 ng ml ${ }^{-1}$ of $\mathrm{CPA}$ and $2.5 \mathrm{ng} \mathrm{ml}^{-1}$ of MPA; and (C) plasma from dosed patient at $T_{24 \mathrm{~h}}$ spiked with $2.5 \mathrm{ng} \mathrm{ml}^{-1}$ of MPA. Precolumn: LiChrospher RP-4 ADS (25 mm $\times 2.0 \mathrm{~mm}$ i.d.), washing liquid: water-acetonitrile-formic acid (90:10:0.1 (v/v/v)) adjusted to $\mathrm{pH} 4.0$ with diluted ammonia, flow-rate: $0.3 \mathrm{ml}$ min ${ }^{-1}$, loading step: $14 \mathrm{~min}$, transfer step: $4 \mathrm{~min}$. Column: OmniSpher C18 $(100 \mathrm{~mm} \times 2.0 \mathrm{~mm}$ i.d. $)(3 \mu \mathrm{m})$, mobile phase: water-methanol-formic acid $(10: 90: 0.1$ (v/v/v)), flow-rate: $0.3 \mathrm{ml} \mathrm{min}{ }^{-1}$, injection volume: $30 \mu \mathrm{l}$ of plasma sample, temperature: $25^{\circ} \mathrm{C}$, MRM mode parameters: as described in Section 2.1 . MPA: medroxyprogesterone acetate; CPA: cyproterone acetate. 
Table 1

Validation results

\begin{tabular}{|c|c|c|c|c|}
\hline & & Day 1 & Day 2 & Day 3 \\
\hline \multicolumn{5}{|l|}{ Response function } \\
\hline & Slope & $3.72 \times 10^{-4}$ & $3.72 \times 10^{-4}$ & $3.71 \times 10^{-4}$ \\
\hline$(k=3, m=6, n=3)$ & Intercept & $5.80 \times 10^{-2}$ & $5.83 \times 10^{-2}$ & $5.75 \times 10^{-2}$ \\
\hline $0.3-50 \mathrm{ng} \mathrm{ml}^{-1}$ & $r^{2}$ & 0.9996 & 0.9996 & 0.9996 \\
\hline Trueness $(k=3 ; n=3)$ & & Absolute bias, $\mathrm{pg} \mathrm{ml}^{-1}$ (relative bias $(\%)$ ) & & \\
\hline $0.3 \mathrm{ng} \mathrm{ml}^{-1}$ & & $3.51(1.2)$ & & \\
\hline $0.5 \mathrm{ng} \mathrm{ml}^{-1}$ & & $-0.72(-0.1)$ & & \\
\hline $1.0 \mathrm{ng} \mathrm{ml}^{-1}$ & & $16.2(1.6)$ & & \\
\hline $10 \mathrm{ng} \mathrm{ml}^{-1}$ & & $-599.7(-6.0)$ & & \\
\hline $25 \mathrm{ng} \mathrm{ml}^{-1}$ & & $620.3(2.5)$ & & \\
\hline $50 \mathrm{ng} \mathrm{ml}^{-1}$ & & $2069(4.1)$ & & \\
\hline Precision $(k=3 ; n=3)$ & Repeatability, R.S.D. (\%) & Intermediate precision, R.S.D. (\%) & & \\
\hline $0.3 \mathrm{ng} \mathrm{ml}^{-1}$ & 1.5 & 1.5 & & \\
\hline $0.5 \mathrm{ng} \mathrm{ml}^{-1}$ & 0.9 & 1.2 & & \\
\hline $1.0 \mathrm{ng} \mathrm{ml}^{-1}$ & 1.2 & 1.6 & & \\
\hline $10 \mathrm{ng} \mathrm{ml}^{-1}$ & 0.5 & 0.5 & & \\
\hline $25 \mathrm{ng} \mathrm{ml}^{-1}$ & 0.4 & 0.4 & & \\
\hline $50 \mathrm{ng} \mathrm{ml}^{-1}$ & 0.4 & 0.4 & & \\
\hline Accuracy $(k=3 ; n=3)$ & & $\beta$-Expectation tolerance limit, $\mathrm{ng} \mathrm{ml}^{-1}(\%)$ & & \\
\hline $0.3 \mathrm{ng} \mathrm{ml}^{-1}$ & & $0.293-0.314(-2.4$ to 4.7$)$ & & \\
\hline $0.5 \mathrm{ng} \mathrm{ml}^{-1}$ & & $0.483-0.516(-3.4$ to 3.1$)$ & & \\
\hline $1.0 \mathrm{ng} \mathrm{ml}^{-1}$ & & $0.968-1.065(-3.2$ to 6.5$)$ & & \\
\hline $10 \mathrm{ng} \mathrm{ml}^{-1}$ & & $9.275-9.525(-7.2$ to -4.7$)$ & & \\
\hline $25 \mathrm{ng} \mathrm{ml}^{-1}$ & & $25.39-25.85(1.6-3.3)$ & & \\
\hline $50 \mathrm{ng} \mathrm{ml}^{-1}$ & & $51.57-52.57(3.1-5.1)$ & & \\
\hline LOQ (ng ml-1) & & 0.3 & & \\
\hline $\operatorname{LOD}\left(\mathrm{ng} \mathrm{ml}^{-1}\right)$ & & 0.12 & & \\
\hline
\end{tabular}

six concentration levels was used and its goodness of fit is illustrated in Fig. 3.

\subsubsection{Trueness}

As can be seen from the results in Table 1 trueness was expressed in terms of absolute bias $\left(\mathrm{pg} \mathrm{ml}^{-1}\right)$ or relative bias $(\%)$ and was assessed by means of validation standards in the matrix at six concentration levels $(m=6)$ ranging from 0.3 to $50.0 \mathrm{ng} \mathrm{ml}^{-1}(k=3, n=3)$. Compared to the regulatory requirements fixed [27], the proposed method was true enough

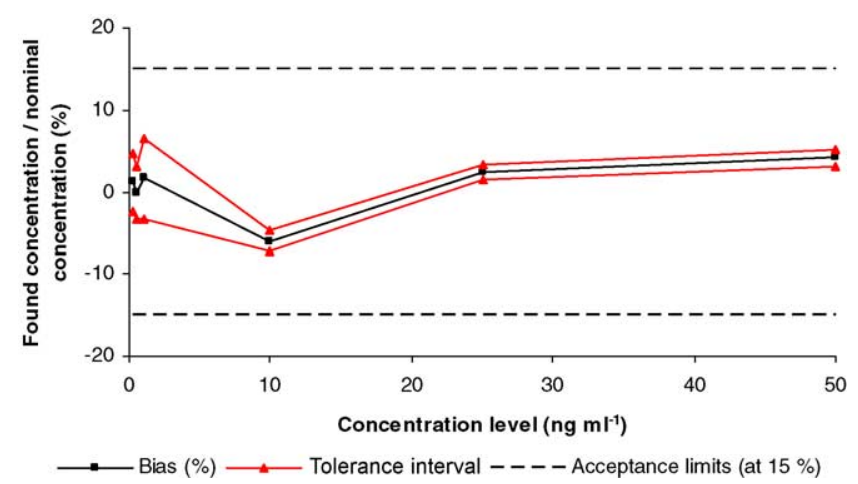

Fig. 3. Accuracy profile obtained in validation by applying weighted linear regression $\left(1 / X^{2}\right)$. since the bias did not exceed the values of $15 \%$ irrespective to the concentration level.

\subsubsection{Precision}

The R.S.D. values presented in Table 1 were very low, the relative standard deviation values for repeatability and intermediate precision were between $0.4 \%$ and $1.6 \%$, illustrating the good precision of the proposed method. However, the method sensitivity could still be improved since the R.S.D. value for the LOQ is very low (1.5\%).

\subsubsection{Accuracy}

The upper and lower $\beta$-expectation tolerance limits expressed in $\mathrm{n} \mathrm{ml}^{-1}$ are presented in Table 1 as a function of the introduced concentrations. As can be seen from the results, the proposed method was accurate, since the different tolerance limits of the bias did not exceed the acceptance limits $( \pm 15 \%)$ [27] for all the concentration levels tested including the lowest one $\left(0.3 \mathrm{ng} \mathrm{ml}^{-1}\right)$.

\subsubsection{Limit of quantification and limit of detection}

As the accuracy profile is comprised within the acceptance limits, the LOQ was fixed to $0.3 \mathrm{ng} \mathrm{ml}^{-1}$, i.e. the smallest concentration level investigated. Indeed, precision and trueness were demonstrated at this concentration level (Table 1). The LOD has been estimated at $120 \mathrm{pg} \mathrm{ml}^{-1}$. 


\subsection{Precolumn lifetime}

In order to maintain an optimal lifetime of both precolumn and analytical column, it is important to pre-centrifuge the plasma samples, to add an organic modifier to the washing liquid used for the fractionation step and to install a replaceable in-line filter located between the sample injector and the precolumn in order to protect the sieves and tubing from clogging. These different recommendations have been taken into account in the analytical protocol. Under the proposed experimental conditions, the precolumn was shown to be work properly for over 1000 injections of $30 \mu l$ of plasma.

\section{Conclusion}

A new fully automated procedure was developed for the LC-MS/MS determination of cyproterone acetate using restricted-access material in a precolumn for sample processing.

The developed method is selective towards endogenous plasma components and the recovery of the analyte is close to $100 \%$. Its accuracy has been also assessed over a concentration range from $0.3 \mathrm{ng} \mathrm{ml}^{-1}$ to $50 \mathrm{ng} \mathrm{ml}^{-1}$ when in our previous work [24] a LOQ of $15 \mathrm{ng} \mathrm{ml}^{-1}$ was reached. Considering the low R.S.D. values for precision, the sensitivity of the method could still be improved. However, a further reduction of the carry over effect should then be needed.

These results demonstrate the applicability of the proposed LC-MS/MS method for the determination of CPA plasma levels in patients treated with relatively low dosages (i.e. $2 \mathrm{mg}$ per day).

\section{Acknowledgements}

Many thanks are due to J.-C. Van Heugen from the Department of Environmental and Industrial Toxicology (University of Liège, Belgium) for his precious aid.

\section{References}

[1] H. Hoja, P. Marquet, B. Verneuil, H. Lotfi, B. Penicaut, G. Lachatre, J. Anal. Toxicol. 21 (1997) 116.

[2] H.H. Maurer, J. Chromatogr. B 713 (1998) 3.

[3] M. Nishikawa, H. Tsuchihashi, J. Toxicol. 17 (1998) 13.

[4] M.-C. Hennion, J. Chromatogr. A 856 (1999) 3.

[5] D. Ortelli, S. Rudaz, S. Souverain, J.-L. Veuthey, J. Sep. Sci. 25 (2002) 222 .

[6] D. Westerlund, Chromatographia 24 (1987) 155.

[7] I.H. Hagestam, T.C. Pinkerton, J. Chromatogr. 351 (1986) 239.

[8] T.C. Pinkerton, J. Chromatogr. 544 (1991) 13.

[9] K.S. Boos, B. Wilmers, R. Sauerbrey, E. Schlimme, Chromatographia 24 (1987) 363.

[10] K.S. Boos, A. Rudolphi, S. Vielhauer, A. Walfort, D. Lubda, F. Eisenbeiss, Fresenius J. Anal. Chem. 352 (1995) 684.

[11] A. Rudolphi, S. Vielhauer, K.S. Boos, D. Seidel, I.M. Bäthge, H. Berger, J. Pharm. Biomed. Anal. 13 (1995) 615.

[12] K.S. Boos, C.H. Grimm, Trends Anal. Chem. 18 (3) (1999) 175

[13] A. Ceccato, B. Toussaint, P. Chiap, Ph. Hubert, J. Crommen, Enantiomer 4 (1999) 305.

[14] P. Chiap, A. Ceccato, R. Gora, Ph. Hubert, J. Géczy, J. Crommen, J. Pharm. Biomed. Anal. 27 (2002) 447.

[15] A.J. Wein, J.J. Murphy, J. Urology 100 (1973) 68.

[16] J. Hammerstein, L. Moltz, U. Schwartz, J. Steroid Biochem. 19 (1) (1983) 591.

[17] http://www.medsafe.govt.nz/Profs/Datasheet/e/Estelle3535EDtab.htm.

[18] A. Segall, M. Vitale, V. Perez, F. Hormaechea, M. Palacios, M.T. Pizzorno, Drug Dev. Ind. Pharm. 26 (8) (2000) 867.

[19] J.C. Scott, R.A. Soltero, J. Chromatogr. Sci. 25 (1987) 415.

[20] L.D. Dikkeshei, B.G. Wolthers, A.W. De Ruyter-Buitenhuis, G.T. Nagel, J. Chromatogr. 529 (1990) 145.

[21] K. Yodo, S. Saisho, K. Shimozawa, J. Yata, Endocrinol. Jpn. 35 (1) (1988) 143

[22] R.G. Frith, G. Phillipou, J. Chromatogr. 338 (1985) 179.

[23] W. Kuhnz, J. Chromatogr. 420 (1987) 432.

[24] B. Christiaens, P. Chiap, O. Rbeida, D. Cello, J. Crommen, Ph. Hubert, J. Chromatogr. B 795 (2003) 73.

[25] Ph. Hubert, J.J. Hguyen-huu, B. Boulanger, E. Chapuzet, P. Chiap, N. Cohen, et al., STP Pharma Pratiques 13 (3) (2003) 101.

[26] B. Boulanger, W. Dewe, P. Chiap, J. Crommen, Ph. Hubert, J. Pharm. Biomed. Anal. 32 (2003) 753.

[27] Department of Health and Human Services Food and Drug Administration, Guidance for Industry, Bioanalytical Method Validation, May 2001. 